\title{
FUNGSI RUANG TERBUKA HIJAU BAGI KENYAMANAN \\ MASYARAKAT AKIBAT PEMANASAN GLOBAL Isu terhadap Masyarakat Kota Surabaya
}

\author{
Endah Yuswarini*
}

\begin{abstract}
Abstrak
Kota Surabaya termasuk kota besar yang cenderung padat, akibat besarnya urbanit yang berdampak pada pertambahan penduduk setiap tahunnya, maka diperlukan kesiagaan mengantisipasi isu tersebut. Pemanasan global adalah meningkatnya suhu rata-rata permukaan bumi akibat pekatnya gas $\mathrm{CO}$ dan $\mathrm{CO} 2$ di angkasa sehingga dibutuhkan penyeimbang berupa tanaman yang ada di kota sebagai penyerap gas tersebut. Tujuan tulisan ilmiah ini adalah memaparkan hasil kajian lapangan secara kualitatif dan kuantitatif berdasarkan sampel yang ditentukan dengan cara purposive accidental sampling. Metode penelitian ini berbasis observasi lapangan, studi literature dan peta. Lokasi kajian di kota Surabaya, obyek yang di teliti adalah Ruang Terbuka Hijau. Pembagian wilayah mewakili dominasi kegiatan masyarakat: perdagangan, pemerintahan, pantai, industri, rekreasi dan permukiman. Klasifikasi ditentukan berdasarkan lokasi yang berhasil teridentifikasi sejumlah 57 titik lokasi atau 65,5\% atas dasar kerapatan tegakan, nisbah kanopi, keanekaragaman dan dominasi tanaman. Hasil kajian berdasarkan kategori terbagi menjadi a). hutan kota hanya $12 \%$, b). kawasan hijau berpohon $36 \%$ dan c). ruang terbuka 52\%. Oleh sebab itu andaikata jumlah seluruh ruang terbuka hijau kota di Surabaya seluas 6.330 ha ( $19,42 \%$ luas kota Surabaya), untuk dimaksimalkan fungsinya agar dapat memberi kenyamanan bagi masyarakat yang signifikan dan dalam menyikapi pemanasan global.
\end{abstract}

Kata Kunci: ruang terbuka hijau,pemanasan global

Kota Surabaya memiliki semboyan yang patriotik, yaitu Suroboyoku bersih dan hijau. Berangkat dari semboyan itu, maka tergugahlah untuk meneruskan pembangunan Surabaya sebagai suistainable city, walaupun kota Surabaya harus dapat memanfaatkan persyaratan utama dalam kebutuhan hidup, yaitu kebutuhan manusia dan makhluk hidup lainnya (hewan dan tumbuhan) membutuhkan zat asam/oksigen (O2) dan membuang gas asam arang (CO2). Dari makhluk hidup yang ada, hanya tumbuhanlah yang dapat menghasilhan $(\mathrm{O} 2)$.

Sesuai fungsi penggunaan lahan, yang ditetapkan oleh Pemerintah Kota Surabaya dalam realisasi ditenggarai terjadi penyimpangan peruntukan lahan seluruh segmen geografis wilayahnya. Pembangunan merupakan suatu proses perubahan sosial ekonomi menuju ke arah yang lebih baik, namun perubahan tidak hanya pada

* Dosen Jurusan Diploma Teknik Sipil FTSP ITS

jsh Jurnal Sosial Humaniora, Vol 3 No.1, Juni 2010 
aspek fisik dan kelembagaan saja namun termasuk perubahan taraf hidup dan derajat pertisipasi masyarakat secara keseluruhan.

Sebagaimana tertuang dalam Rencana Strategi Daerah Kota Surabaya (Renstrada Kota Surabaya) 2002-2005, bahwa visi kota Surabaya adalah "Surabaya Metropolitan Madani 2010”. Upaya dalam mengembangkan segenap potensinya untuk menjadi sebuah kota yang siap melayani dalam menyediakan kebutuhan dan kepentingan dasar yang diperlukan dalam mendukung proses kehidupan dan penghidupan warga kotanya, menjadi perwujudan visi dalam pengembangan Wawasan Pembangunan Kota yang berbasis Budiparamarinda (budaya, pendidikan, pariwisata, maritim, industri, dan perdagangan (Tondojekti, 2003).

Salah satu kegiatan strategis untuk mendukung pelaksanaan program peningkatan kualitas lingkungan kota tersebut adalah pengendalian pencemaran air, tanah dan udara, berdasarkan Rencana Strategi Daerah Kota Surabaya dalam kaitannya dengan peningkatan kualitas lingkungan kota yang menetapkan beberapa kegiatan strategis dengan sasaran terciptanya lingkungan kota yang indah, sejuk dan nyaman serta bebas polusi.

Penjabaran kegiatan pengendalian pencemaran udara nasional merupakan arahan dan pedoman yang sangat penting untuk pengendalian pencemaran udara di daerah sesuai Peraturan Pemerintah Republik Indonesia No.41 Tahun 1999, tentang Pengendalian Pencemaran Udara, telah diatur hak dan kewajiban setiap anggota masyarakat serta setiap pelaku usaha/kegiatan agar dalam setiap langkah kegiatannya tetap terjaga dalam memelihara kelestarian fungsi lingkungan hidup.

Kota Surabaya dewasa ini hanya memiliki 2,255 atau 736 hektar ruang terbuka hijau (Wijoyo, 2004), padahal hutan kota sebaiknya 20\% hingga 30\% dari luas kota. Untuk Surabaya minimal 30\% hutan kota. Sementara itu kebutuhan akan ruang terbuka hijau 10,03 $\mathrm{m}^{2} /$ orang yang diproyeksikan untuk tahun 2011 berdasarkan jumlah penduduk dibutuhkan 5.037 hektar ruang terbuka hijau $(13,80 \%)$ (Sugiyono, 2003). Andaikata luas kota Surabaya $362 \mathrm{~km}^{2}$, maka luas ruang terbuka paling tidak seluas 9.000 hektar.

Setiap tahun/bulan jumlah kendaraan bermotor terus meningkat dengan pesat, disisi lain muncul gas buang/emisi kendaraan bermotor. Informasi dari pabrik 
siap memproduksi 10.000 kendaraan bermotor (Jatipermata, 2006). Produksi tersebut baru satu tipe, belum tipe-tipe yang lain dan dari pabrik-pabrik yang lain, yang mengakibatkan meningkatnya polusi udara akibat emisi gas buang yang dihasilkan. Emisi gas buang mengandung zat kimia yang membahayakan paru-paru manusia, diantaranya timbal, kabon dan sebagainya. Salah satu cara yang relatif efektif dan efisien untuk mengurangi dampak negatif akibat gas emisi kendaraan bermotor tersebut adalah dengan membangun taman kota yang setara dengan hutan kota. Disamping itu juga menfungsikan ruang terbuka yang diikuti oleh mamajemen tata guna lahan yang tepat.

\section{Perumusan Masalah}

Berdasarkan latar tersebut diatas, permasalahan dalam kajian ini dirumuskan sebagai berikut :

1. Bagaimanakah aktualitas lahan terbuka hijau dan hutan kota di Surabaya?

2. Bagaimana solusi yang tepat untuk merefungsionalisasikan ruang terbuka sebagai hutan kota?

\section{Maksud dan Tujuan}

Maksud diadakan kajian ini adalah untuk memberikan akurasi data mengenai ruang terbuka di Kota Surabaya

Tujuannya adalah sebagai berikut :

1. Mengidentifikasi aktualitas lahan terbuka hijau/hutan kota di Surabaya

2. Mengetahui efektifitas Perda tentang Ruang Terbuka Hijau

3. Mengetahui antisipasi kebijakan pengeluaran berbagai perijinan atas manajemen tata guna lahan

4. Menemukan solusi yang tepat untuk merefungsionalisasi hutan kota

\section{Ruang Lingkup}

Ruang lingkup kajian ini adalah identifikasi aktualitas lahan terbuka hijau dan atau hutan kota, evaluasi efektifitas Perda Kota Surabaya, tentang ruang terbuka hijau, antisipasi kebijakan pengeluaran perijinan tata guna lahan, dan menemukan solusi yang tepat guna merefungsionalisasikan hutan kota Surabaya. 
Kajian ini difokuskan pada kondisi hutan kota di Surabaya. Pokok kajiannya adalah bagaimana kondisi hutan kota khususnya dan ruang terbuka hijau umumnya saat ini. Jika dapat dialihfungsikan maka diupayakan dapat dikembalikan pada fungsinya semula.

Secara eksplisit tidak ada data tentang letak dan luas lahan kota, baik yang tergambar dalam peta maupun yang tertulis secara statistik. Dalam beberapa referensi hutan kota termasuk dalam kawasan ruang terbuka hijau (RTH), seperti hijauan yang lain, pertamanan kota, rekreasi kota, pemakaman, pertanian, jalur hijau dan pekarangan.

Sebagai sumber data utama dalam kajian ini adalah peta ruang terbuka hijau (RTH), dan semua data yang berkaitan dengan RTH. Peta yang digunakan dalam kajian adalah Peta Kota Surabaya tahun 2001, yang secara keseluruhan menggambarkan keberadaan RTH di tiap kecamatan. Dari peta yang dikaji diketahui bahwa di seluruh kota Surabaya terdapat 556 titik berdasarkan beberapa pertimbangan baik teknis maupun non teknis, tidak semua titik dikaji walaupun semua titik diambil sampelnya.

\section{Pencemaran Udara dan Penanggulangannya}

Perbandingan campuran beberapa macam gas dalam udara bersih

\begin{tabular}{|l|l|c|}
\hline No & Nama Gas & Prosentase \\
\hline 1. & Nitrogen (N2) & 78 \\
2. & $\begin{array}{l}\text { Oksigen (O2) } \\
\text { Argon (Ar), Karbon dioksida(CO2), } \\
\text { Helium, Neon, Krypton, Hydrogen, } \\
\text { Ozon, Xenon }\end{array}$ & 1 \\
\hline 4 & Jumlah gas dalam udara bersih & 100 \\
\hline
\end{tabular}

Dalam keadaan normal, udara bersih mengandung zat-zat lainnya dalam jumlah yang sangat sedikit, sehingga dianggap tidak ada. Sebaliknya dalam keadaan 
tercemar, udara mengandung gas-gas berbahaya melebihi batas yang dapat ditoleransi (Hegemer, 2003).

3 (Tiga) kelompok pencemar udara :

\begin{tabular}{|l|l|l|}
\hline No & Pencemaran Udara & Pencemar \\
\hline 1. & Secara Fisika & Debu, bau busuk, suhu panas \\
2. & Secara Biologi & $\begin{array}{l}\text { Kuman penyakit yang } \\
\text { berterbangan di udara. }\end{array}$ \\
3. & Secara Kimia & $\begin{array}{l}\text { Gas buang kendaraan } \\
\text { Asap pabrik } \\
\text { Pembakaran Sampah yang } \\
\text { berlebihan }\end{array}$ \\
\hline
\end{tabular}

Semua zat pencemar udara dapat membahayakan kesehatan, zat pencemar fisika mudah dirasakan sehingga mudah untuk dihindari, sebaliknya zat pencemar kimia dan biologi tidak mudah dirasakan akibatnya tidak mudah dihindari. Umumnya pencemar kimia (gas buang kendaraan bermotor, asap pabrik) lebih berbahaya karena mengandung racun (Hegemer, 2003).

Peraturan Daerah Kota Surabaya, tentang Pemeriksaan Emisi Kendaraan Bermotor (2003), mengatur gas buang yang dihasilkan oleh kendaraan bermotor setiap kendaraan yang beroperasi di jalan di wilayah Kota Surabaya wajib memenuhi ambang batas emisi gas buang kendaraan bermotor (pasal 2), untuk kendaraan pribadi (pasal 3);

Kandungan karbon monooksida (CO) karbon hidrokarbon (HC) serta ketebalan asap pancaran gas buang/emisi

\begin{tabular}{|l|l|l|}
\hline No & Macam Kendaraan Bermotor & Prosentase \\
\hline 1. & $\begin{array}{l}\text { Sepeda motor 2(dua) langkah dengan } \\
\text { bahan bakar bensin dengan bilangan } \\
\text { oktana 87 }\end{array}$ & $\begin{array}{l}\text { Maksimal 4,5\% CO } \\
3000 \text { ppm HC }\end{array}$ \\
2. & $\begin{array}{l}\text { Sepeda motor 4(empat) langkah dengan } \\
\text { bahan bakar bensin dengan bilangan } \\
\text { oktana 87 }\end{array}$ & $\begin{array}{l}\text { Maksimal 4,5\% CO } \\
\text { 3. } 400 \text { ppm HC }\end{array}$ \\
$\begin{array}{l}\text { Kendaraan bermotor selain sepeda motor } \\
\text { dengan bahan bakar bensin dengan } \\
\text { bilangan oktana 87. }\end{array}$ & 1200 ppm HC \\
\hline
\end{tabular}




\begin{tabular}{|l|l|l|}
\hline 4. & Kendaraan bermotor selain sepeda motor & Maksimal eqivalen \\
dengan bahan bakar solar/diesel dengan & $50 \%$ bosch pada \\
bilangan etana 45. & $\begin{array}{l}\text { diameter } 102 \mathrm{~mm} \text { atau } \\
25 \% \text { ketebalan asap. }\end{array}$ \\
\hline
\end{tabular}

Secara holistik, masalah pencemaran udara Kota Surabaya, antara lain :

a. Perbandingan yang tidak seimbang antara kemampuan penambahan ruas jalan dengan laju penambahan jumlah kendaraan bermotor yang berdampak pada kemacetan lalu lintas ruas jalan tertentu. Hal ini akan memberikan kontribusi terhadap peningkatan pencemaran udara.

b. Masih ada kendaraan dengan emisi gas buang melebihi batas ambang

c. Belum seimbangnya luas ruang terbuka hijau dengan luas lahan dengan jumlah penduduk. (Abubakar,2003)

\section{Fungsi Hutan Kota}

Kehadiran pepohanan dalam lingkungan kehidupan manusia khususnya di perkotaan, memberikan nuansa tersendiri. Pengaturan mengenai eksistensi hutan kota, umumnya dicakup dalam peraturan daerah tentang ruang terbuka hijau termasuk taman kota (berbagai tipe) dan hutan kota.

Definisi Hutan Kota, didefinisikan sebagai tumbuhan atau vegetasi kayu di wilayah perkotaan yang memberikan manfaat lingkungan dalam kegunaan proteksi, estetika, rekreasi dan lainnya (Fakuara, 1987).

Hasil rumusan rapat teknis tentang kota (1999), mendefinisikan: suatu hamparan lahan yang ditumbuhi pepohonan yang kompak dan rapat di wilayah perkotaan di atas tanah milik Negara atau tanah yang difungsikan sebagai penyangga lingkungan dalam pengaturan tata air, udara, habitat flora/fauna yang memiliki estetika dengan luasan yang solid yang merupakan kumpulan pohon-pohon termasuk ruang terbuka hijau yang ditetapkan oleh pejabat berwenang sebagai hutan kota.

Menurut Instruksi Menteri Dalam Negeri No.14 Tahun 1988, hutan kota merupakan bagian dari perwujudan program ruang terbuka hijau (RTH), sebagai ruang-ruang dalam kota atau wilayah yang lebih luas dalam penggunaanya lebih bersifat terbuka dan pada dasarnya tanpa bangunan. 
Pengadaan hutan kota saat ini belum menjadi perhatian utama dari para pengelola kota. Penghijauan kota masih cenderung mengutamakan nilai estetika saja, sehingga yang terbentuk adalah taman-taman kota dengan tanaman perlu rumput yang tertata rapi dan teratur serta bersih, dalam arti tidak banyak pohon besar yang dapat mengganggu penampilan taman tersebut. Jenis penghijauan ini kurang memberi manfaat secara optimal bagi kenyamanan lingkungan. Pemeliharaan hutan kota akan lebih bermanfaat sebagai penyeimbang lingkungan.

Pemantauan fisik kota dalam Program Bangun Praja 2004-2005, ruang terbuka hijau terdiri dari hutan kota dan taman kota. Penentuan hutan kota adalah hutan di dalam wilayah kota yang memiliki luas minimal 0,25 hektar dan atau sudah ditetapkan sebagai hutan kota oleh Peraturan Daerah. Pemantauan lokasi hutan memperhatikan kerapatan tegakan pepohonan dan keteduhan atau nisbah antara luas luas tajuk (canopy) dibandingkan luas arealnya (Program Bangun Praja,2005).

Manfaat tanaman hutan kota sebagai penghijauan kota dapat diidentifikasikan sebagai:

a. Pengontrol udara disekitarnya, termasuk mendinginkan udara dan mengatur kecepatan angin.

b. Pencegah erosi tanah, mengurangi polusi udara dan suara.

c. Sebagai habitat burung dan satwa liar lainnya.

d. Sebagai tempat rekreasi

e. Sebagai tempat pendidikan tentang alam

f. Sebagai variasi/pergantian suasana di dalam kota

g. Sebagai panorama/ bentang alam.

Keberadaan tanaman khususnya pohon besar sangat diperlukan dalam wilayah kota, dalam upaya mengurangi polusi udara yang berasal dari industri dan lalu lintas kota. Polutan yang paling penting dan dapat diserap adalah yang berbentuk gas dan partikel. Hal ini akan terjadi disebabkan karena tanaman dikenal sebagai penghasil oksigen pada saat berfotosintesis. Pada saat proses oksigenisasi yaitu saat mengeluarkan oksigen ke udara maka polutan-polutan udara yang berada di dekat tanaman akan bercampur dengan oksigen baru tersebut sehingga tingkat/ kadar polusi akan berkurang.(Yuswarini, Endah.2009). 
Pemilihan jenis pohon yang diutamakan dan disesuaikan dengan iklim kota Surabaya, antara lain :

a. Pohon besar bercabang banyak dan berakar tunggang

b. Berbatang kayu keras

c. Berdaun lebat, membentuk payung/kanopi

d. Berumur panjang

e. Berbuah atau tidak berbuah (Rahmi et.al, 1999)

Contoh pohon yang dapat ditanam sebagai hutan kota, adalah: mahoni, kenari, trembesi, asem jawa, karena memiliki batang kayu yang keras dan kuat serta masa hidupnya relatif lama, cara penanamannya sambil menunggu besarnya pohon diselingi pohon jenis lain yang cepat tumbuh.

\section{Metodologi}

Diawali dengan pengukuran kondisi Hutan Kota dan Ruang Terbuka Hijau diterapkan terhadap indikator yang terdiri dari :

a. Perbandingan antara luas kanopi dengan luas kondisi ideal

b. Keanekaragaman dan dominasi tanaman

c. Kerapatan Tegakan

d. Dominasi Tanaman

Dilanjutkan dengan mengklasifikasikan kondisi Hutan Kota dan Ruang Terbuka Hijau seperti tabel dibawah ini :

Tabel.II.1

\begin{tabular}{|c|c|c|}
\hline \multicolumn{2}{|c|}{ Perbandingan antara luas kanopi dengan luas kondisi ideal } \\
\hline Interval \% Kanopi & Klasifikasi & Skor \\
\hline$>60 \%$ & Baik & 3 \\
$30 \%-60 \%$ & Sedang & 2 \\
$<30 \%$ & Tidak Baik & 1 \\
\hline
\end{tabular}

Tabel.II.2

\begin{tabular}{|c|c|c|}
\hline \multicolumn{2}{|c|}{ Keaneka ragaman dan dominasi tanaman } \\
\hline Keragaman & Klasifikasi & Skor \\
\hline$>4$ jenis pohon & Heterogen & 3 \\
$2-4$ jenis pohon & Sedang & 2 \\
1 jenis pohon & Homogen & 1 \\
\hline
\end{tabular}


Tabel.II.3

\begin{tabular}{|c|c|c|}
\hline \multicolumn{2}{|c|}{ Kerapatan Tegakan } \\
\hline Kerapatan/Tegakan & Klasifikasi & Skor \\
\hline $1-3$ meter & Rapat & 3 \\
$4-6$ meter & Agak Rapat & 2 \\
$>6$ meter & Tidak Rapat & 1 \\
\hline
\end{tabular}

Tabel.II.4

\begin{tabular}{|l|c|c|}
\hline \multicolumn{2}{|c|}{ Dominasi Tanaman } \\
\hline Dominasi Tanaman & Klasifikasi & Skor \\
\hline Pohon > non pohon & Hutan Kota & 3 \\
Pohon < non pohon & Kawasan Hijau & 1 \\
\hline
\end{tabular}

Hasil perhitungan skor Tabel. $1 \mathrm{~s} / \mathrm{d}$ 4, diperoleh skor ideal tertinggi yaitu 12 dan terendah 4, maka disusunlah klasifikasi di Tabel.5

Tabel.II.5

\begin{tabular}{|c|c|}
\hline \multicolumn{2}{|c|}{ Klasifikasi Tipe RTH } \\
\hline Rentang Skor & Tipe \\
\hline $10-12$ & Hutan Kota \\
$7-9$ & Kawasan Hijau Berpohon \\
$4-6$ & Ruang Terbuka Non Hutan Kota \\
\hline
\end{tabular}

\section{Populasi dan Sampel}

1. Populasi

Kapadatan ditinjau dari kepadatan permukiman, zonasi wilayah terbangun di Surabaya terbagi menjadi 5 wilayah, antara lain:

a. Wilayah Surabaya Utara, didominasi kegiatan perdagangan dan transportasi

b. Wilayah Surabaya Timur, mayoritas kegiatan pantai, tambak, mangrove serta industry dan transportasi

c. Wilayah Surabaya Tengah, didominasi kegiatan pemerintahan

d. Wilayah Surabaya Barat, didominasi permukiman baru lengkap dengan transportasi dengan ruang terbuka

e. Wilayah Surabaya Selatan, didominasi kegiatan industri dan perdagangan, serta perkantoran baru dan transportasi 
2. Sampel

Pemilihan sampel secara purposive dan accidental /insidentil dapat mewakili karakteristik populasi di atas sesuai lokasinya, karena kesulitan mencari lokasi yang tepat dalam peta Ruang Terbuka Hijau di Surabaya. Untuk itu dikaji berdasarkan kecamatan sebagai wakil uji, diantaranya adalah sebagai berikut, lihat tabel.II.7 :

\begin{tabular}{|c|l|l|c|c|}
\hline No & Wilayah / Kecamatan & \multicolumn{1}{|c|}{ Kegiatan } & $\begin{array}{c}\text { Titik } \\
\text { kajian }\end{array}$ & $\begin{array}{c}\text { Prosenta } \\
\text { se Data }\end{array}$ \\
\hline 1. & $\begin{array}{l}\text { Surabaya Utara, } \\
\text { Pabean Cantikan }\end{array}$ & $\begin{array}{l}\text { Perdagangan dan } \\
\text { transportasi }\end{array}$ & 8 & $100 \%$ \\
\hline 2. & $\begin{array}{l}\text { Surabaya Selatan, } \\
\text { Rungkut }\end{array}$ & Industri dan transportasi & $\begin{array}{l}\text { Dari 17 } \\
\text { terkaji 5 }\end{array}$ & $30 \%$ \\
\hline 3, & $\begin{array}{l}\text { Surabaya Timur, } \\
\text { Sukolilo }\end{array}$ & $\begin{array}{l}\text { Pertanian } \\
\text { tambak/nelayan, } \\
\text { permukiman dan } \\
\text { transportasi }\end{array}$ & 14 & $87 \%$ \\
\hline 4 & $\begin{array}{l}\text { Surabaya Tengah, } \\
\text { Genteng }\end{array}$ & $\begin{array}{l}\text { Pemerintahan/perkantor } \\
\text { an,pertokoan } \\
\text { transportasi }\end{array}$ & 14 & $100 \%$ \\
\hline 5 & $\begin{array}{l}\text { Surabaya Barat, } \\
\text { Sukomanunggal }\end{array}$ & $\begin{array}{l}\text { Permukiman teratur dan } \\
\text { transportasi }\end{array}$ & $\begin{array}{c}\text { Dari 22 } \\
\text { terkaji } 9\end{array}$ & $41 \%$ \\
\hline
\end{tabular}

Dari 5 kecamatan yang mewakili dengan 87 titik berhasil diidentifikasi sebanyak 57 titik atau 65,5\%. Penelaahan sampel melalui Nomogram King (1988), cukuprepresentatif walaupun masih terjadi error sebesar 7\% dari $10 \%$ yang oleh metodologis masih diizinkan (Tuckman, 1988).

\section{Metode Pengumpulan Data}

Metode observasi, merupakan metode pengumpulan data yang terpilih dalam mendokumentasi kajian ini, meliputi :

a. Perda tentang Ruang Terbuka Hijau berikut cara dokumentasi

b. Kebijakan Perijinan atas Tata Guna Lahan berikut cara dokumentasi

c. Badan Perencanaan Kota Surabaya, berikut Luas total wilayah tebangun

d. Kondisi Ruang Terbuka HIJAU atau Hutn Kota yang dikumpulkan melalui observasi 
Data Primer yang dikaji adalah butir d. sedang indikator yang terdata meliputi luas area, keanekaragaman tanaman, kerapatan tegakan, dan perawatannya.

\section{Metode analisa Data}

Data yang telah terkumpul untuk dianalisa dengan cara diskriptif, kemudian disajikan dalam tabel prosentase. Data tersebut dilengkapi analisa spasial pada Peta Ruang Terbuka Hijau Kota Surabaya dan diterbitkan oleh Dinas Lingkungan Hidup Kota Surabaya tahun 2001.

\section{Hasil dan Pembahasan}

\section{Deskripsi Wilayah Studi}

Secara administratif kota Surabaya terbagi menjadi 5(lima) wilayah Pembantu Walikota dengan rincian : 31 wilayah kecamatan dan 163 wilayah kelurahan.

Dengan berjalannya waktu, ternyata luas lahan terbangun dari 56,4\% dari 32.000 hektar menjadi 57,5\% (Badan Perencanaan Pmbangunan Kota Surabaya, 2001) dan didominasi oleh permukiman dan jasa. Mengingat UU No.24 Tahun 1992 tentang Tata Ruang, menyebutkan bahwa " Area terbangun disbanding area terbuka tidak melebihi $60: 40$ "

\section{Kondisi Ruang Terbuka Hijau}

Melalui penelitian di lapangan dilengkapi data dokumentasi maka hasil rekapitulasi dapat disajikan pada Tabel III.1 dibawah ini:

Tabel. III.1 Rekapitulasi Kajian

\begin{tabular}{|c|l|c|c|c|}
\hline Wilayah & \multicolumn{1}{|c|}{ Wakil Kecamatan } & $\begin{array}{c}\text { Hutan } \\
\text { Kota }\end{array}$ & $\begin{array}{c}\text { Kawasan } \\
\text { Hijau }\end{array}$ & $\begin{array}{c}\text { Ruang } \\
\text { Terbuka }\end{array}$ \\
\hline $\begin{array}{c}\text { Surabaya Utara } \\
(8 \text { ttk/100\%) }\end{array}$ & $\begin{array}{l}\text { Pabean Cantikan : } \\
\text { Perdagangan }\end{array}$ & $25 \%$ & $25 \%$ & $50 \%$ \\
\hline $\begin{array}{c}\text { Surabaya Timur } \\
(19 \text { ttk/58\%) }\end{array}$ & $\begin{array}{l}\text { Sukolilo } \\
\text { Pantai , Permukiman }\end{array}$ & $10 \%$ & $40 \%$ & $50 \%$ \\
\hline $\begin{array}{c}\text { Surabaya Barat } \\
(9 \text { ttk/41\%) }\end{array}$ & $\begin{array}{l}\text { Sukomanunggal } \\
\text { Industri }\end{array}$ & $11 \%$ & $33 \%$ & $56 \%$ \\
\hline $\begin{array}{c}\text { Surabaya Selatan } \\
(5 \text { ttk/30\% })\end{array}$ & $\begin{array}{l}\text { Rungkut } \\
\text { Industri }\end{array}$ & $14 \%$ & $43 \%$ & $43 \%$ \\
\hline $\begin{array}{c}\text { Surabaya Tengah } \\
(14 \text { ttk/ 100\% })\end{array}$ & $\begin{array}{l}\text { Gubeng } \\
\text { Pemerintahan }\end{array}$ & & $60 \%$ \\
\hline
\end{tabular}


Berdasarkan hasil pada Tabel III.6 , maka dapat dinyatakan bahwa kondisi Ruang Terbuka Hijau di kota Surabaya tidak comfortable, sebab hanya 12\% kondisi hutan kota, antara lain :

1. Area jalan Perak Timur, luas $48.063 \mathrm{~m}^{2}$ tipe taman kota dengan beragam tanaman : trembesi, angsana dan soka. Kerapatan 1 meter, tajuk tertutup 90\%, permukaan tanah tertutup rumput.

2. Area jalan Yos Sudarso, kecamatan Genteng Luas $11.875 \mathrm{~m}^{2}$ tipe tanaman: palem, angsana, sawo yang terawat, kurang rapat dan subur serta penutup tanah paving block. Kondisi kawasan hijau berpohon $36,2 \%$, namun tidak berfungsi sebagai hutan kota.

3. Kawasan permukiman di Sukomanunggal, tipe taman kurang terawat dengan baik, dilengkapi balai rukun tetangga luas $1300 \mathrm{~m}^{2}$, tanaman jenis kembang sepatu dan palem yang tidak subur.

Direncanakan Hutan Kota di 7(tujuh) lokasi yang tersebar dibeberapa wilayah kecamatan, yaitu :

1. Prapen Indah: hutan ekologi sosial $\left(4300 \mathrm{~m}^{2}\right)$.

2. Pandugo Panjaringansari: hutan estetika $\left(5000 \mathrm{~m}^{2}\right)$

3. Kebon bibit Wonorejo: hutan ekologi sosial $\left(15.000 \mathrm{~m}^{2}\right)$

4. Tikur PLN Wonorejo: hutan ekologi sosial (3 hektar)

5. Babat Jerawat: hutan ekologi sosial (1,2 hektar) dan ekologi komersial (2 hektar).

6. Kebraon: hutan ekologi sosial (1,5 hektar)

Hasil interpretasi Citra Satelit menyebutkan Wilayah Terbangun Kota Surabaya seluas : 13.704 hektar atau 42,04\% dari luas kota Surabaya $326 \mathrm{~km}^{2}$.

Sedangkan Luas Ruang Terbuka Hijau 6.330 hektar atau 14,42\%. Dengan kata lain prosentase RTH sebenar cukup luas walaupun masih kurang sesai ideal sebesar 20\%. Namun kondisinya masih perlu ditangani sebagai fungsi hutan kota yaitu sebagai penyangga lingkungan dalam hal pengaturan tata air, udara, flora dan fauna, yang memiliki estetika dan rekreasi sesuai harapan dalam menyerap gas CO2 dan CO. 


\section{Kesimpulan}

1. Aktualisasi Ruang Terbuka Hijau di Surabaya belum memenuhi target yang sesuai dengan Perda Kota Surabaya No.7 tahun 2002.

2. Peraturan yang terkait sudah tersedia, namun belum sepenunya dilaksanakan warga masyarakat.

3. Luas Terbangun sudah cukup tinggi, namun masih ada yang mendirikan bangunan tanpa melalui Ijin Mendirikan Bangunan.

4. Perlu ada gerakan dalam merawat RTH, walaupun di area jalur utama menjadi tanggung jawab Dinas Kebersihan, mensosialisasikan Perda No.7 tahun 2002 tentang Pengelolaan RTH secara intensif.

5. Penting untuk memaksimalkan fungsi Hutan Kota untuk memproduksi O2 dan mengoptimalkan fungsi rekreasi.

6. Membangun kembali area RTH dan HK yang sudah alih fungsi.

\section{Daftar Pustaka}

Abubakar, M.2003. "Pengelolaan Kualitas Udara di Kota Surabaya.Makalah Workshop Stakeholders Participation on Air Quality Improvement in Surabaya, 26-28 Agustus 2003.

Badan Perencanaan Pembangunan Kota Surabaya, 2001, Laporan Akhir Pengembangan Pusat Data Perencanaan dan Pengendalian Pembangunan di Kota Surabaya, Penyusun Basis Data Digital (GIS) .

Fakuara, 1987, Hutan Kota dalam Kumpulan Jurnal LAN

Hegemer,CJ. 2003 Modul Udara.Materi Pendidikan Lingkungan Hidup, Hans Seidel Foudation, Jakarta

Program Bangun PRAJA, 2004-2005, "Tata Cara Pemantauan Fisik Kabupaten/ Kota Program Bangun Praja. Kementrian Lingkungan Hidup Republik Indonesia Jakarta.

Jatipermata,T.2005. Cukup 21 Detik dan Motorpun Siap Dikendarai, Harian Surya,2005 
175 - Fungsi Ruang Terbuka Hijau 6agi Kenyamanan Masyarakat ......

Rahmi DH \& B,Setiawan, 1999. Perancangan Kota Ekologi,Ditjen Dikti. Depdikbud, Jakarta.

Yuswarini, Endah (2009), Evaluasi Strategi Manajemen Ruang Terbuka Hijau: Kasus Infrastuktur Hijau di Surabaya Makalah Seminar Nasional Aplikasi Teknologi Prasana Wilayah

Yeang, Ken. (1995). Designing with Nature : The Ecological Baic for Architectural Design, Mc Graw-Hill,Inc, New York.

Peta Ruang Terbuka Hijau (RTH0 Kota Surabaya skala 1:5000, Penerbit Dinas Lingkungan Hidup Kota Surabaya. 